\title{
Erratum to: Terrorism Psychology: Theory \& Application
}

\author{
Alex W. Stedmon • Glyn Lawson
}

Published online: 3 August 2013

(C) Springer Science+Business Media New York 2013

Erratum to: J Police Crim Psych (2012)

DOI 10.1007/s11896-012-9108-4

Since this editorial was published, and in the preparation of the final version of the special issue, the referenced paper by Stedmon et al. has been withdrawn and will be published elsewhere. The following paragraph should be deleted from the article:

With a unique study investigating suspect interrogation scenarios in which individuals were engaged in deceptive activities, Stedmon et al. present evidence that stressed individuals secrete a volatile steroid-based marker that could form the basis for remote detection. In this way, a human pheromone linked to deception may exist and the findings provide a validated model of scalable interrogation that can be used by other researchers to test interventions aimed at detecting or deterring hostile intent.

The online version of the original article can be found at http://dx.doi.org/ 10.1007/s11896-012-9108-4.

\footnotetext{
A. W. Stedmon $(\triangle)$

Cultural, Communications and Computing Research Institute,

Sheffield Hallam University,

Sheffield S1 2NU, UK

e-mail: alex.stedmon@nottingham.ac.uk
}

\begin{abstract}
A. W. Stedmon
e-mail: c3ri@shu.ac.uk
\end{abstract}

G. Lawson

Human Factors Research Group,

Faculty of Engineering University of Nottingham,

Nottingham NG7 2RD, UK 